\title{
REVIEW
}

\section{The fluid management of adults with severe malaria}

\author{
Josh Hanson 1,2*, Nicholas M Anstey ${ }^{1}$, David Bihari ${ }^{3}$, Nicholas J White ${ }^{2,4}$, Nicholas P Day ${ }^{2,4}$ and Arjen M Dondorp ${ }^{2,4}$
}

\begin{abstract}
Fluid resuscitation has long been considered a key intervention in the treatment of adults with severe falciparum malaria. Profound hypovolemia is common in these patients and has the potential to exacerbate the acidosis and acute kidney injury that are independent predictors of death. However, new microvascular imaging techniques have shown that disease severity correlates more strongly with obstruction of the microcirculation by parasitized erythrocytes - a process termed sequestration. Fluid loading has little effect on sequestration and increases the risk of complications, particularly pulmonary edema, a condition that can develop suddenly and unpredictably and that is frequently fatal in this population. Accordingly, even if a patient is clinically hypovolemic, if there is an adequate blood pressure and urine output, there may be little advantage in infusing intravenous fluid beyond a maintenance rate of 1 to $2 \mathrm{~mL} / \mathrm{kg}$ per hour. The optimal agent for fluid resuscitation remains uncertain; significant anemia requires blood transfusion, but colloid solutions may be associated with harm and should be avoided. The preferred crystalloid is unclear, although the use of balanced solutions requires investigation. There are fewer data to guide the fluid management of severe vivax and knowlesi malaria, although a similar conservative strategy would appear prudent.
\end{abstract}

\section{Introduction}

More than $10 \%$ of adults with severe falciparum malaria (SFM) requiring ICU admission will die from the disease [1]. As this population is almost universally hypovolemic $[2,3]$ and the severity of lactic acidosis and the presence of acute kidney injury (AKI) on admission to the hospital are strong prognostic indicators [1,4], it has seemed intuitive that any volume deficit in these patients should be promptly corrected.

The implementation of guidelines that include early, aggressive fluid loading of patients with bacterial sepsis improves outcomes [5]. In the resource-poor setting, prompt fluid resuscitation is a life-saving therapy for conditions as diverse as dengue shock syndrome and cholera [6,7]. However, unlike these conditions, hypotension is relatively infrequent in SFM and is not necessarily associated with increased mortality [8]. Furthermore, fluid loading has a limited effect on the obstructed

\footnotetext{
* Correspondence: drjoshhanson@gmail.com

'Menzies School of Health Research, Royal Darwin Hospital, Rocklands Drive, Tiwi, NT 0810, Australia

${ }^{2}$ Mahidol-Oxford Tropical Medicine Research Unit, Faculty of Tropical

Medicine, Mahidol University, 420/6 Rajvithi Road, Bangkok 10400, Thailand

Full list of author information is available at the end of the article
}

microvascular circulation which is central to disease pathogenesis [9], and as adults with SFM have a generalized increase in vascular permeability [10], fluid loading may lead to complications. In the pulmonary circulation, this can result in acute pulmonary edema (APO), which is often fatal in these patients [11].

As recently as 2010, World Health Organization (WHO) treatment guidelines observed that in adults, there is a very thin dividing line between over-hydration, which may produce APO, and under-hydration contributing to shock, worsening acidosis and renal impairment' [12]. Against this backdrop, the best approach for clinicians caring for patients has been unclear, resulting in lively debate [13,14]. However, recent studies in adults and children with SFM can now offer some guidance.

\section{Review}

\section{Assessing volume status}

The clinical assessment of a patient's volume status is notoriously unreliable $[15,16]$. In SFM, it is even more challenging as physical signs of hypovolemia - including tachycardia, oliguria, and confusion - can result from the disease itself. In the PRISM (PiCCO-guided Resuscitation in Severe Malaria) study, in which 28 critically ill, hypovolemic Bangladeshi and Indian adults with SFM 
received fluid resuscitation guided by transpulmonary thermodilution, physical examination failed to identify patients who were either volume-responsive or at greater risk of APO [17]. Recognizing the limitations of the physical examination, the 2010 WHO treatment guidelines empirically recommended using a central venous catheter $(\mathrm{CVC})$ in critically ill patients and a target central venous pressure (CVP) of 0 to $5 \mathrm{~cm} \mathrm{H}_{2} \mathrm{O}$ [12]. However, in the Vietnamese Hemodynamic Study (VHS) of 24 adults with SFM who received fluid loading guided by pulmonary artery occlusion pressure (PAOP), there was no relationship between CVP and cardiac output either before or after fluid resuscitation, and almost half the patients with an admission CVP of not more than $0 \mathrm{~cm} \mathrm{H} \mathrm{H}_{2} \mathrm{O}$ were not volume-responsive [18]. Similarly, in PRISM, there was no relationship between CVP and cardiac output before or after fluid resuscitation, and almost $40 \%$ of those patients with a CVP of not more than $0 \mathrm{~cm} \mathrm{H}_{2} \mathrm{O}$ were not volume-responsive [19].

A CVP of between 0 and $5 \mathrm{~cm} \mathrm{H}_{2} \mathrm{O}$ also failed to protect patients against APO: the majority of patients in PRISM and VHS with APO on enrollment had a CVP of not more than $5 \mathrm{~cm} \mathrm{H}_{2} \mathrm{O}[18,19]$. There were similar findings in a Thai series and in smaller series of imported malaria [20-22]. These observations and the additional risks of using CVCs have led the WHO to rescind their recommendation for CVP-guided fluid resuscitation [23]. This has coincided with a growing skepticism about the utility of the CVP to guide fluid resuscitation in other critically ill populations [24].

So where does this leave the clinician? Physical findings cannot be ignored, but if used to guide fluid resuscitation, they need to be interpreted cautiously and informed by repeated assessment, clinical judgment, and laboratory and radiological investigations. In one series, transpulmonary thermodilution appeared to be helpful as monitoring of extravascular lung water (EVLW) during fluid loading promptly identified incipient APO [25], but further study is required to define its optimal role.

\section{Contribution of volume status to clinical manifestations}

Yet even if hypovolemia can be accurately identified, recent data suggest a relatively limited pathological role in adults with SFM. Every patient in PRISM was hypovolemic on admission when assessed with transpulmonary thermodilution, yet the more hypovolemic patients were actually less acidotic. Renal function was also unrelated to volume status on admission; indeed, after 24 hours of fluid resuscitation, the more hypovolemic patients had lower plasma creatinine concentrations [25]. In VHS, patients with lower systemic oxygen delivery $\left(\mathrm{DO}_{2}\right)$ had neither greater acidosis nor renal impairment [18], whereas in a small Thai series, patients admitted with AKI had a normal blood volume [26].
Instead, it is the changes at a microvascular level, including sequestration, endothelial dysfunction, and changes in blood rheology, that appear more important [27] (Figure 1, Additional file 1). Sequestration - the process in which parasitized erythrocytes pack the microcirculation, avoiding clearance by the spleen but physically obstructing blood flow - correlated with plasma lactate concentrations before and after resuscitation in PRISM [25] and on admission in two other Bangladeshi series [28,29]. Meanwhile, autopsy studies have shown greater renovascular sequestration in SFM patients with AKI [30].

Conversely, features of SFM that might be attributed to fluid excess usually exist in the absence of volume overload. Overzealous fluid resuscitation will exacerbate APO, but in PRISM, 70\% of patients were hypovolemic at the time it developed and the remainder were euvolemic [25]. Adults with cerebral malaria are universally hypovolemic at presentation; cerebral edema can occur, but this tends to be in the agonal setting as part of a multi-organ dysfunction syndrome [31].

\section{Effects of fluid resuscitation: acidosis and renal dysfunction}

Two series - PRISM and VHS - examined the response of adults with SFM to fluid resuscitation in detail (Table 1) [18,25]. In PRISM, patients received a total of 81 fluid challenges (targeting a global end-diastolic volume index (GEDVI) of more than $680 \mathrm{~mL} / \mathrm{m}^{2}$ ) but were volume-responsive (increase in cardiac index by more than $15 \%$ ) on only $28 \%$ of these occasions; meanwhile, $50 \%$ of the patients in VHS were volume-responsive to their single fluid challenge (which targeted a PAOP of 9 to $12 \mathrm{~mm} \mathrm{Hg}$ ). There was no clinically meaningful increase in $\mathrm{DO}_{2}$ with fluid resuscitation in either study. More importantly, there was no significant improvement in acidosis, an important finding as acid-base status at admission was the strongest prognostic indicator in both series. Hyperchloremia from the chloride-rich fluid load partly explained these findings, but the most important explanation appears to be the limited effect of fluid resuscitation on microvascular sequestration, the principal cause of the acidosis. Despite 6 hours of liberal fluid loading in PRISM, 91\% of patients still had visible sequestration and in 35\% the degree of sequestration was unchanged or had increased. Sequestration was still visible in almost half of those assessed at 48 hours [25].

The persisting acidosis also resulted from the fluid load's failure to significantly improve renal function. In PRISM, no anuric patient regained a urine output with fluid loading and $75 \%$ later required renal replacement therapy (RRT). In the patients with significant renal impairment still passing urine, $50 \%$ had an increase in plasma creatinine despite 24 hours of fluid resuscitation. In VHS, renal function was as likely to deteriorate in the patients receiving a fluid bolus as in those who did not [18]. 


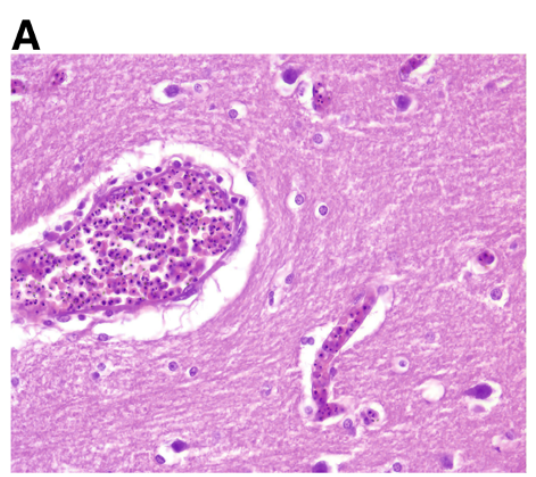

C

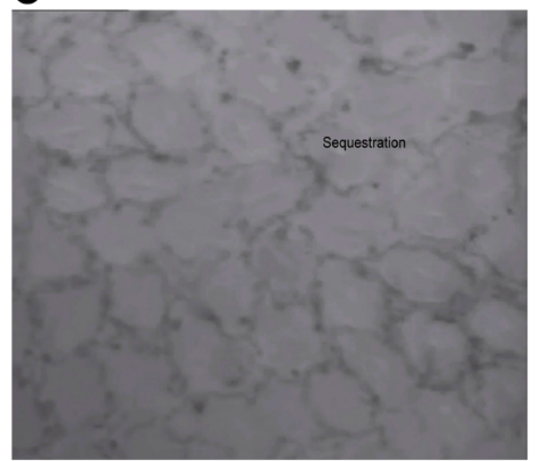

B

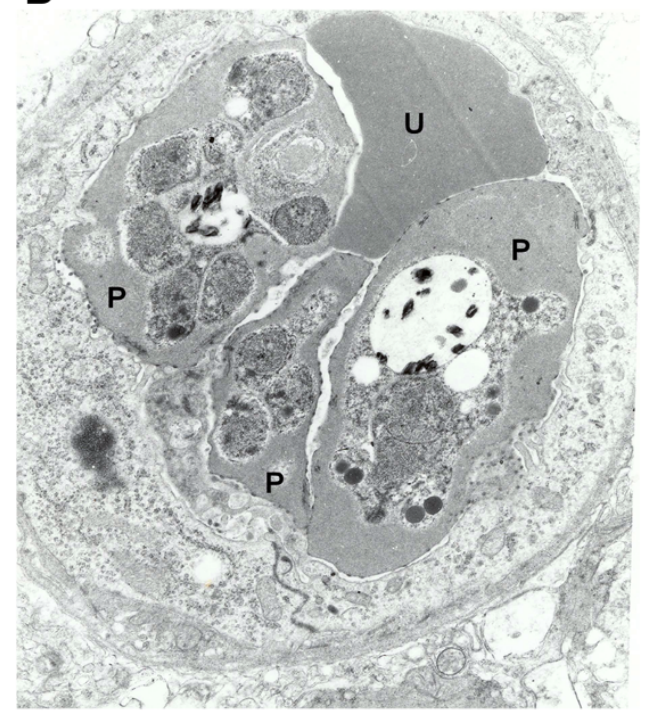

Figure 1 The appearance of microvascular sequestration with the use of different imaging techniques. (A) Photomicrograph of a brain section from an adult Vietnamese patient who died with cerebral malaria, demonstrating blood vessels packed with parasitized erythrocytes (hematoxylin-eosin stain, magnification $\times 400$, courtesy Gareth Turner). (B) An electron micrograph of a capillary demonstrating microvascular obstruction. Parasitized erythrocytes (P) obstruct the passage of an uninfected erythrocyte (U) (courtesy of Emsri Pongponratn). (C) Still from an orthogonal polarization spectral imaging video (Additional file 1) of a patient with severe falciparum malaria, showing the cobblestone pattern of the capillaries surrounding the rectal crypts. The polarization filter causes red structures to appear dark grey, hence erythrocytes are visible as grey spots; their movement can be measured by using image-analysis software. The presence of sequestration is suggested in vessels where there is no erythrocyte movement.

In other series, the strongest predictor of a salutary renal response to fluid resuscitation was the renal function on admission. Only $5 \%$ of anuric patients regained a urine output with fluid loading and diuretics in a Vietnamese series [32]. In a series of Bangladeshi patients receiving fluid resuscitation guided by clinical assessment, two thirds with significant renal impairment later required RRT [33]. Patients with milder renal impairment are more likely to respond, but kidney function can still deteriorate. In the Bangladeshi series, 7.4\% with a normal plasma creatinine on admission later required RRT [33]. In an Indian series, 11\% of those without renal failure on admission later developed the complication [34]. Renal tubular injury is proportional to the duration and extent of renal hypoperfusion, and the failure of fluid resuscitation to improve renal function may be due to delays in its initiation. However, sequestration also leads to tubular hypoperfusion, and its persistence despite fluid and anti-malarial therapy $[25,35]$ may again explain why AKI continues to evolve in some patients.

\section{Pulmonary edema and cerebral malaria}

In PRISM, $74 \%$ of patients developed clinical or volumetric (EVLW of at least $10 \mathrm{~mL} / \mathrm{kg}$ ) evidence of APO during resuscitation. All patients were hypovolemic or euvolemic (normal GEDVI) at the point that APO developed [25]. Fluid loading was more conservative in VHS, and clinical APO occurred less frequently [18]. These findings suggest that increased pulmonary vascular permeability is common in adults with SFM and that the risk of APO is increased by liberal fluid loading.

There is little pathological or radiological evidence that vasogenic edema plays a major role in the pathogenesis of cerebral malaria [31,36], a principle supported by an absence of clinical evidence of cerebral edema in any of the patients in PRISM [25] and the absence of neurological deterioration in any of the patients receiving fluid loading in VHS [18].

\section{Other clinical findings}

After 24 hours of fluid resuscitation, almost $90 \%$ of patients in the PRISM study were still hypovolemic and 
Table 1 Response to fluid resuscitation in the two series to specifically examine the issue in adults with severe falciparum malaria

\begin{tabular}{|c|c|c|c|c|c|c|}
\hline & \multicolumn{3}{|c|}{ VHS $^{a}[18]$} & \multicolumn{3}{|c|}{ PRISM $^{\mathbf{b}}[25]$} \\
\hline & Baseline & Post-resuscitation $^{c}$ & Change & Baseline & Post-resuscitation $^{c}$ & Change \\
\hline \multirow[t]{2}{*}{ Plasma bicarbonate, $\mathrm{mmol} / \mathrm{L}$} & 13.9 & 12.8 & -0.1 & 16.9 & 12.1 & -1.9 \\
\hline & (10.5 to 17$)$ & (11.2 to 17.3$)$ & $(-1$ to 1$)$ & (13.8 to 17.8$)$ & (13.7 to 15.4$)$ & $(-3.7$ to -0.6$)$ \\
\hline \multirow[t]{2}{*}{ Plasma lactate, $\mathrm{mmol} / \mathrm{L}$} & 6.3 & 6.3 & -0.1 & 3.2 & 1.7 & -1 \\
\hline & (2.7 to 9 ) & (2.7 to 9 ) & $(-0.6$ to 0.4$)$ & (1.9 to 5.4$)$ & (1.4 to 3.1$)$ & $(-1.8$ to 0.3$)$ \\
\hline \multirow[t]{2}{*}{$\overline{\mathrm{pH}^{\mathrm{d}}}$} & 7.36 & 7.35 & -0.01 & 7.34 & 7.31 & -0.05 \\
\hline & (7.29 to 7.41$)$ & (7.29 to 7.39$)$ & $(-0.01$ to 0.01$)$ & (7.32 to 7.37$)$ & (7.24 to 7.34$)$ & $(-0.1$ to 0.1$)$ \\
\hline \multirow[t]{2}{*}{ Base deficit, mEq/L } & 11 & 13 & 0.6 & 9 & 13 & 3 \\
\hline & (7 to 13 ) & (6 to 14$)$ & (0.3 to 1.8$)$ & (8 to 12 ) & (10 to 14$)$ & (0 to 5$)$ \\
\hline \multirow[t]{2}{*}{$\overline{\text { Strong ion gap, } \mathrm{mEq} / \mathrm{L}^{\mathrm{e}}}$} & - & - & - & 11.2 & 12.4 & 1.2 \\
\hline & & & & (7.2 to 15.2$)$ & (9.4 to 15.2 ) & $(-2.1$ to 3.6$)$ \\
\hline \multirow[t]{2}{*}{$\mathrm{CVP}, \mathrm{cm} \mathrm{H} \mathrm{H}_{2} \mathrm{O}$} & 2 & 5 & 3 & 5 & 10 & 6 \\
\hline & (0 to 4$)$ & (3 to 6$)$ & (0 to 6$)$ & (-2 to 8$)$ & (7 to 14$)$ & (1 to 10$)$ \\
\hline \multirow[t]{2}{*}{ PAOP, $\mathrm{mm} \mathrm{Hg}^{f}$} & 6 & 11 & 5 & - & - & - \\
\hline & (4 to 7$)$ & (8 to 12$)$ & (2 to 8$)$ & & & \\
\hline \multirow[t]{2}{*}{ Heart rate, beats per minute } & 115 & 111 & -6 & 101 & 99 & 0 \\
\hline & (100 to 130$)$ & (94 to 119) & $(-11$ to 0$)$ & (93 to 112 ) & (90 to 110 ) & (-11 to 9$)$ \\
\hline \multirow[t]{2}{*}{ Glasgow Coma Scale score ${ }^{g}$} & 8 & - & - & 12 & 14 & 0 \\
\hline & (6 to 13$)$ & & & (8 to 15$)$ & (8 to 15$)$ & (0 to 2$)$ \\
\hline \multirow[t]{2}{*}{ MAP, mm Hg } & 79 & 79 & 1 & 88 & 94 & 7 \\
\hline & (71 to 85 ) & (74 to 89 ) & $(-2$ to 7$)$ & (79 to 98 ) & (82 to 108 ) & $(-2$ to 17$)$ \\
\hline \multirow[t]{2}{*}{ Cardiac index, $\mathrm{L} / \mathrm{min}$ per $\mathrm{m}^{2}$} & 4.06 & 5 & 0.63 & 3.08 & 3.64 & 0.49 \\
\hline & (3.23 to 4.82 ) & (3.8 to 5.49 ) & (0.15 to 1.06$)$ & (2.84 to 3.28$)$ & (3.38 to 4.13 ) & (0.18 to 1.13$)$ \\
\hline \multirow[t]{2}{*}{$\overline{\mathrm{DO}_{2}} \mathrm{l}, \mathrm{mL} / \mathrm{min}$ per $\mathrm{m}^{2}$} & 454 & 470 & 18 & 421 & 403 & 15 \\
\hline & (341 to 557 ) & (371 to 578 ) & $(-21$ to 87$)$ & (348 to 482 ) & (331 to 532 ) & (-90 to 86$)$ \\
\hline \multirow[t]{2}{*}{ SVRI, dynes-sec/cm per $\mathrm{m}^{2}$} & 1,430 & 1,174 & -139 & 2,155 & 1,926 & -203 \\
\hline & $(1,193$ to 2,039$)$ & (945 to 1,874 ) & $(-434$ to -25$)$ & $(1,779$ to 2,532$)$ & $(1,552$ to 2,320$)$ & $(-751$ to 170$)$ \\
\hline \multirow[t]{2}{*}{ Hemoglobin, g/dL } & 8.8 & 7.4 & -0.7 & 10.4 & 9.1 & -1.6 \\
\hline & 7.2 to 10.8 & (6.1 to 9.7 ) & $(-1.6$ to -0.1$)$ & (8.5 to 12.6$)$ & (7.1 to 10.5$)$ & $(-2.5$ to -0.2$)$ \\
\hline \multirow[t]{2}{*}{$\mathrm{SaO}_{2} / \mathrm{FiO}_{2}$ ratio } & 436 & 484 & 0 & 455 & 443 & -9 \\
\hline & (374 to 575 ) & (360 to 552 ) & $(-25$ to 25$)$ & (306 to 467 ) & (271 to 462$)$ & $(-23$ to 2$)$ \\
\hline \multirow[t]{2}{*}{$\overline{G E D V I, ~ m L / m^{2 e}}$} & - & - & - & 472 & 585 & 91 \\
\hline & & & & (429 to 571 ) & (539 to 638) & (10 to 126$)$ \\
\hline \multirow[t]{2}{*}{ EVLW, mL/kge } & - & - & - & 8 & 10 & 1 \\
\hline & & & & (6 to 9$)$ & (8 to 11$)$ & (1 to 3 ) \\
\hline \multirow[t]{2}{*}{$\overline{\mathrm{PVPl}^{\mathrm{e}}}$} & - & - & - & 2.29 & 2.25 & 0.05 \\
\hline & & & & (1.82 to 2.45$)$ & (1.97 to 2.6$)$ & $(-0.16$ to 0.32$)$ \\
\hline \multirow[t]{2}{*}{ Plasma creatinine, $\mu \mathrm{mol} / \mathrm{L}^{\mathrm{g}}$} & 339 & - & - & 158 & 132 & -26 \\
\hline & (220 to 572$)$ & & & (106 to 255$)$ & (88 to 211 ) & $(-62$ to 18$)$ \\
\hline
\end{tabular}

Values are presented as the median (interquartile range). ${ }^{a}$ Median (range) of 3,230 mL $(1,035$ to 7,000 ) over the initial 6 hours and $5,450 \mathrm{~mL}(1,985$ to 13,720 ) over

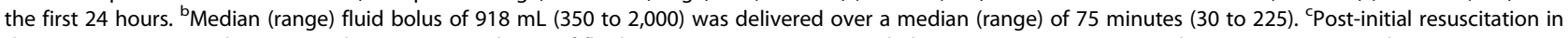
the Vietnamese Hemodynamic Study (VHS), post- 6 hours of fluid resuscitation in PiCCO-guided Resuscitation in Severe Malaria (PRISM) except plasma creatinine

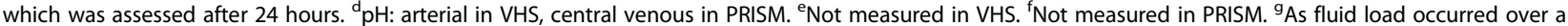
median of only 75 minutes in VHS, Glasgow Coma Scale score and plasma creatinine were not repeated immediately post-resuscitation. CVP, central venous pressure; $\mathrm{DO}_{2}$ l, oxygen delivery; EVLW, extravascular lung water; GEDVI, global end-diastolic volume index; MAP, mean arterial pressure; PAOP, pulmonary artery occlusion pressure; PVPI, pulmonary vascular permeability index; $\mathrm{SaO}_{2} / \mathrm{FiO}_{2}$, oxygen saturation (percentage)/fraction of inspired oxygen; SVRI, systemic vascular resistance index. 
most had developed marked generalized peripheral edema. The patients with marked edema were more likely to develop APO and were more likely to die. Notably, in the first 24 hours, there was a median fall in the intravascular volume of the patients who later died compared with a median increase in survivors [25]. The mechanism for this generalized edema is uncertain, although endothelial activation and dysfunction probably contribute. Plasma angiopoietin- 2 concentrations correlate with outcome and disease severity in adults with malaria [37]. Endothelial activation and sequestration may also disrupt the endothelial glycocalyx, diminishing vascular integrity [38].

\section{Role of intensive care unit support}

However, despite the documented harm of fluid resuscitation, survival in PRISM and VHS was better than expected when controlled for disease severity [4]. This was particularly notable in VHS, in which patients received relatively inferior anti-malarial therapy (quinine or artemether). Rather than suggesting any occult benefit of fluid resuscitation, this more likely reflects the two studies' ICU setting which facilitated access to supportive care and well-trained clinicians. In the well-resourced ICU, mortality rates of adults with SFM are much lower $[1,39]$.

Resuscitation strategies should also be judged by the ease with which their complications can be remedied. It may be better to err on the side of under-hydrating adults with SFM as APO can occur suddenly and unpredictably and is frequently fatal even if mechanical ventilation is available. Conversely, AKI develops less abruptly and has a greater therapeutic window, allowing referral to nephrology services, where it has a better response to treatment.

Despite the availability of mechanical ventilation, $89 \%$ of Indian patients with an arterial partial pressure of oxygen/fraction of inspired oxygen $\left(\mathrm{PaO}_{2} / \mathrm{FiO}_{2}\right)$ ratio of less than $200 \mathrm{~mm} \mathrm{Hg}$ died in one large series [34] and $70 \%$ of Thai patients with a $\mathrm{PaO}_{2} / \mathrm{FiO}_{2}$ ratio of less than $100 \mathrm{~mm} \mathrm{Hg}$ died in another [22]. Over 60\% of South African patients with APO died despite mechanical ventilation [40], and even in European national referral hospitals, patients die from malaria-related APO [39]. Conversely, in patients with AKI requiring RRT, mortality fell from $75 \%$ to $26 \%$ with a mean duration of 3 days of peritoneal dialysis (PD) [32]. When hemofiltration was compared with PD in Vietnamese patients with AKI and severe infection (69\% of whom had SFM), patients receiving hemofiltration had a mortality of only $15 \%$ and a faster resolution of acidosis and required RRT for fewer days [41].

\section{Multi-organ dysfunction syndrome}

Although there is a tendency to categorize adults with SFM as either 'dry' and at increased risk of acidosis and
AKI or 'wet' and at increased risk of APO, this appears too simplistic an approach. Multi-organ involvement is the rule in the patients with the most severe disease. Fluid management is challenging in these patients, although again a more conservative approach is more likely to be beneficial [42].

In one Indian SFM series, $69 \%$ of adults with both AKI and APO died, the case-fatality rate was $14 \%$ if APO occurred in isolation, and there were no deaths in patients with only AKI [43]. In another Indian study, the risk of death increased with both renal failure and respiratory failure, but all patients with AKI alone survived and no patient in the series had APO in isolation [34]. In a South African series, 7 out of 8 deaths occurred in patients with concomitant AKI and APO [40], whereas in a French series, most patients with APO had multiorgan involvement ( $83 \%$ had AKI) and were more likely to die [44]. In a Portuguese series, over three quarters of the deaths occurred in patients with concurrent AKI and APO [45], and in PRISM all of the patients who died had APO while anuric [25]. In a British series, the only patient whose death was directly attributable to malaria died of multi-organ failure with concomitant AKI and APO [39].

\section{Lessons from pediatric malaria}

SFM has a different clinical spectrum in adults and children: in adults, coma duration is longer, severe anemia is less frequent, and AKI and APO are much more common [46]. However, there are important similarities in pathophysiology in the two populations, particularly the fundamental role of sequestration. In studies examining the fluid resuscitation of adults and children with SFM, there are many comparable findings.

Although hypovolemia is present in children with SFM, it is relatively mild when assessed by using standardized measures and is not commensurate with the degree of end-organ pathology. Gabonese children with SFM were only mildly dehydrated when assessed isotopically; despite this, over half had a plasma lactate of more than $5 \mathrm{mmol} / \mathrm{L}$ [47]. Retinal changes consistent with sequestration have been documented in children with SFM and correlate with outcome and sequestration seen at autopsy [48-50]. These findings suggest that, as in adults, sequestration and endothelial dysfunction can explain the clinical manifestations of disease in children without hypovolemia being invoked.

The fluid resuscitation of children with SFM has been explored on a larger scale than in adults, culminating in the landmark FEAST (Fluid Expansion as Supportive Therapy) study [51]. Here, febrile African children with clinical evidence of hypoperfusion (57\% with P. falciparum parasitemia) were randomly assigned on admission to the hospital to receive boluses of either 20 to $40 \mathrm{~mL} / \mathrm{kg}$ of $5 \%$ albumin or $0.9 \%$ saline or to receive no boluses; standard 
care was otherwise provided. The mortality was increased to a similar degree in the children receiving an albumin or saline bolus (relative risk of death: 1.59) compared with the control group.

A retrospective analysis suggested that the increased mortality resulted from cardiovascular collapse rather than fluid overload per se, although this conclusion was somewhat hampered by limited data regarding the participants' deaths. The mechanism for this cardiovascular collapse was unclear, although a rapid reduction in sympathetically mediated compensatory mechanisms and treatment-induced hyperchloremic metabolic acidosis were suggested. Although APO and increased intracranial pressure were suspected in some patients, neither was identified frequently [52].

\section{Lessons from the critical care literature}

The hazards of fluid resuscitation are well recognized, and fluid excess has been linked to increased mortality in several critically ill adult populations [53-57]. Various hypotheses have been proposed to explain these findings. Up to $80 \%$ of a crystalloid bolus leaves the intravascular space of volunteers within an hour of its administration
[58,59], and this figure may be higher in critically ill adults in whom increased capillary permeability is common [60]. The resulting tissue edema might lead to organ dysfunction by obstructing capillary and lymphatic flow and impairing oxygen and metabolite diffusion $[61,62]$.

Liberal fluid resuscitation is one of the central, albeit controversial, components of the Surviving Sepsis Guidelines $[63,64]$. Although adherence to the guidelines improves outcomes [65], assessing the contribution of fluid resuscitation is complicated by the fact that it is delivered as one component of a bundle of care including antibiotics, vasopressors, and expert medical and nursing care; an independent benefit of fluid resuscitation was not identified in several studies $[66,67]$. Meanwhile, in patients with acute lung injury, a restrictive fluid strategy has been shown to improve oxygenation without an increased incidence of shock or RRT requirement [42].

Even if a patient is fluid-responsive, simply increasing $\mathrm{DO}_{2}$ is not necessarily associated with improved outcomes [68]. If there is an adequate cardiac output and mean arterial pressure - as was the case in the majority of patients in PRISM and VHS even prior to fluid loading - what are we expecting any extra administered fluid to do?

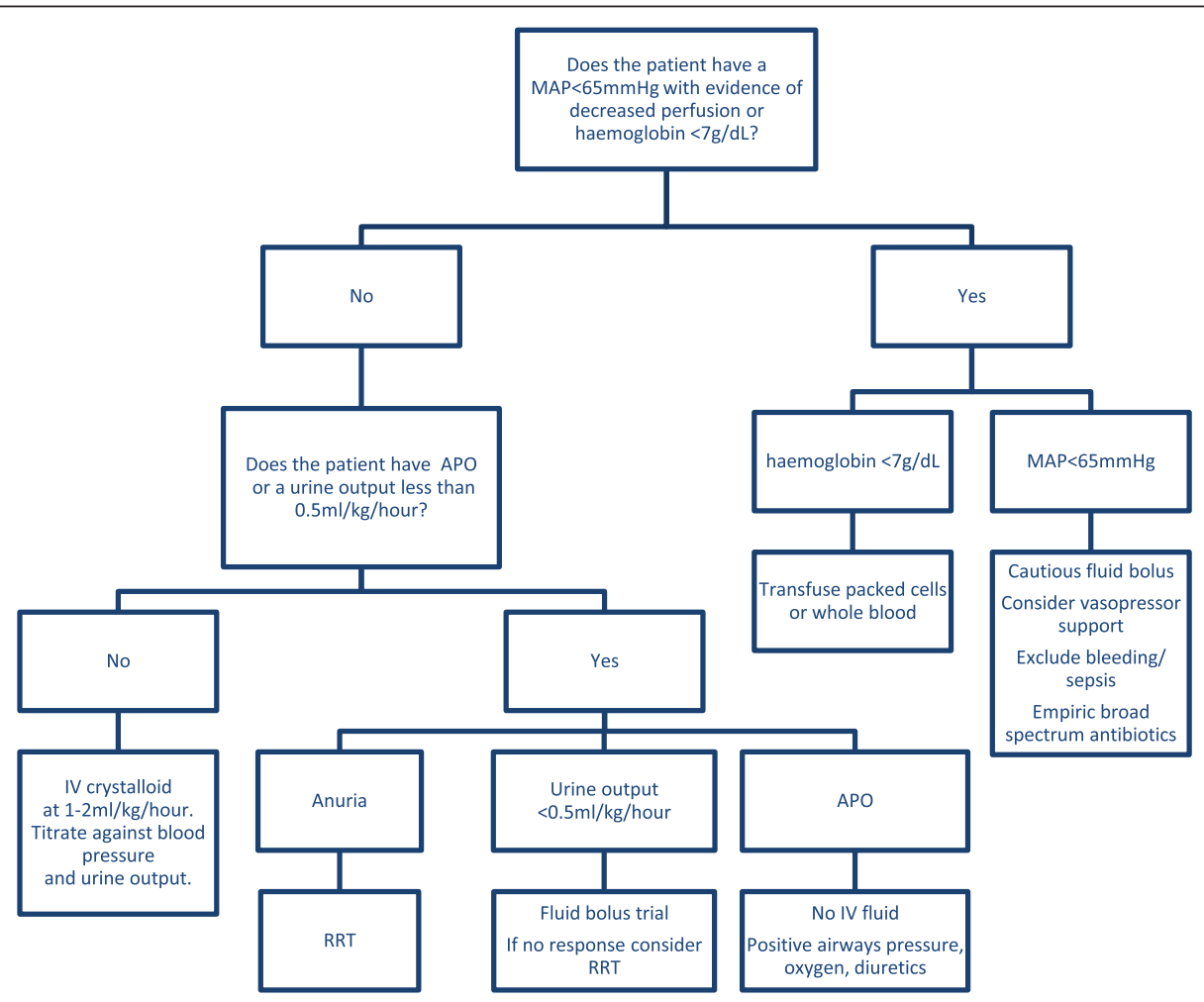

Figure 2 Suggested fluid management for adults with severe malaria. All of the proposed supportive care measures may not be available at sites where patients with severe malaria are initially managed. Early transfer to centers where these services are available is indicated, when possible. Maintenance fluid: the suggested 1 to $2 \mathrm{~mL} / \mathrm{kg}$ per hour should take into consideration and include other administered fluids: antibiotic therapy, vasopressor infusions, and so on. Crystalloid: Based on plasma electrolytes, consider balanced solutions if available. Fluid bolus: $5 \mathrm{~mL} / \mathrm{kg}$ crystalloid over 15 minutes; titrate bolus frequency against clinical response. APO, acute pulmonary edema; IV, intravenous; MAP, mean arterial pressure; RRT, renal replacement therapy, hemofiltration preferred if available. 


\section{Optimal resuscitation fluid}

The WHO recommends $0.9 \%$ saline to rehydrate adults with malaria, although recent concerns about the association between the use of chloride-rich fluids and acidosis and AKI may be relevant [69]. Although balanced solutions have shown survival benefit in some ICU populations [70], they have yet to be trialed in malaria. Few clinical data support the use of colloids in critically ill populations $[71,72]$. The fact that some preparations are associated with an increased risk of AKI and bleeding is concerning given the incidence of these complications in SFM. Against this background, the current WHO recommendation to treat shocked patients with plasma expanders may need revision [23]. As children receiving albumin in the FEAST study had an increased mortality, it cannot be recommended in adults with malaria [51]. The WHO empirically recommends a threshold for transfusion of $7 \mathrm{~g} / \mathrm{dL}$ in adults with SFM.

\section{Suggested fluid resuscitation strategy}

There is no single fluid prescription appropriate for all adults with SFM. The disease's protean manifestations occur in a range of patients with a variety of comorbidities. However, in general, the available data support a conservative fluid resuscitation strategy (Figure 2). Although simple extrapolation to adults is not possible, children in the control arm of the FEAST study had the lowest mortality and received a cumulative median fluid load of only $10 \mathrm{~mL} / \mathrm{kg}$ in the first 8 hours [51].

In the minority of adults with SFM in whom it occurs, shock remains a medical emergency, necessitating thorough assessment for concomitant bacterial infection (with initiation of broad-spectrum antibiotics) and exclusion of occult bleeding. In these patients, prompt fluid resuscitation with frequent reassessment remains the standard of care with early vasopressor support if required. Patients with a hemoglobin level of below $7 \mathrm{~g} / \mathrm{dL}$ should receive fresh blood or packed cells. As anemia often evolves during treatment, clinicians should anticipate a transfusion requirement in those with more modest anemia.

If patients are anuric, fluid resuscitation is unlikely to lead to a recovery of renal function and early RRT is recommended. In the setting of AKI and oliguria, small fluid boluses $(5 \mathrm{~mL} / \mathrm{kg}$ titrated against effect) could be trialed, although clinicians should maintain a low threshold for initiating RRT. However, if an adult with SFM has adequate blood pressure (mean arterial blood pressure of more than $65 \mathrm{~mm} \mathrm{Hg}$ ) and urine output (more than $0.5 \mathrm{~mL} / \mathrm{kg}$ per hour), there appears little advantage in prescribing any fluid beyond crystalloid at a maintenance rate of 1 to $2 \mathrm{~mL} / \mathrm{kg}$ per hour, with the selection of crystalloid therapy guided by plasma electrolytes.

\section{Other malaria species}

Plasmodium vivax and Plasmodium knowlesi can both cause severe disease, although sequestration is not prominent in either infection and the relative contribution of co-morbidities to clinical manifestations, particularly in vivax, is uncertain [73,74]. However, both infections can cause APO with a clinical phenotype similar to that seen in SFM. No studies of fluid resuscitation in patients with vivax or knowlesi infection have been performed, though given the risk of APO, a conservative fluid regimen with early RRT and vasopressor support is recommended.

\section{Conclusions}

The optimization of volume status is a fundamental aspect of critical care, and liberal fluid resuscitation is life-saving in many conditions. However, in falciparum malaria, a disease with a unique pathophysiology, it is hazardous and fails to address the microvascular obstruction seen in the disease. Adults with SFM usually have an acceptable cardiac output and blood pressure and are frequently not volume-responsive; any extra administered fluid tends to accumulate in the interstitial space, potentially exacerbating the already impaired end-organ perfusion. Liberal fluid loading in adults leads to no meaningful improvement in the acidosis and AKI and increases the incidence of APO, and in children it increases mortality in the resource-poor setting. Despite the theoretical appeal of promptly correcting hypovolemia in adults with severe malaria, clinicians caring for patients should follow the old malariologist's adage and 'run them dry'.

\section{Additional file}

Additional file 1: An orthogonal polarization spectral imaging video of a patient with severe falciparum malaria.

\section{Abbreviations}

AKI: Acute kidney injury; APO: Acute pulmonary edema; CVC: Central venous catheter; CVP: Central venous pressure; $\mathrm{DO}_{2}$ : Oxygen delivery; EVLW: Extravascular lung water; FEAST: Fluid Expansion as Supportive Therapy; GEDVI: Global end-diastolic volume index; $\mathrm{PaO}_{2} / \mathrm{FiO}_{2}$ : Arterial partial pressure of oxygen/fraction of inspired oxygen; PAOP: Pulmonary artery occlusion pressure; PD: Peritoneal dialysis; PRISM: PiCCO-guided Resuscitation in Severe Malaria; RRT: Renal replacement therapy; SFM: Severe falciparum malaria; VHS: Vietnamese Hemodynamic Study; WHO: World Health Organization.

\section{Competing interests}

The authors declare that they have no competing interests.

\section{Authors' contributions}

$J \mathrm{H}$ wrote the first draft and all authors reviewed and edited the subsequent drafts. All authors read and approved the final manuscript.

\section{Acknowledgments}

$\mathrm{JH}$ and NMA are supported by the National Health and Medical Research Council of Australia. NJW, NPD, and AMD are supported by the Wellcome Trust as part of the Wellcome Trust-Mahidol University-Oxford Tropical Medicine Research Programme. Neither funding body played any role in the collection, analysis, and interpretation of data; in the writing of the review; or in the decision to submit the review for publication. 


\section{Author details}

1 Menzies School of Health Research, Royal Darwin Hospital, Rocklands Drive, Tiwi, NT 0810, Australia. ${ }^{2}$ Mahidol-Oxford Tropical Medicine Research Unit, Faculty of Tropical Medicine, Mahidol University, 420/6 Rajvithi Road, Bangkok 10400, Thailand. 3Prince of Wales Hospital, Barker Street, Randwick, NSW 2031, Australia. ${ }^{4}$ Centre for Tropical Medicine, Nuffield Department of Medicine, University of Oxford Roosevelt Drive, Oxford OX3 7FZ, UK.

\section{Published online: 21 November 2014}

\section{References}

1. Bruneel F, Tubach F, Corne P, Megarbane B, Mira JP, Peytel E, Camus C, Schortgen F, Azoulay E, Cohen Y, Georges H, Meybeck A, Hyvernat H, Trouillet JL, Frenoy E, Nicolet L, Roy C, Durand R, Le Bras J, Wolff M, Severe Imported Malaria in Adults (SIMA) Study Group: Severe imported falciparum malaria: a cohort study in 400 critically ill adults. PLoS One 2010, 5:e13236.

2. Davis TM, Krishna S, Looareesuwan S, Supanaranond W, Pukrittayakamee S, Attatamsoonthorn $\mathrm{K}$, White NJ: Erythrocyte sequestration and anemia in severe falciparum malaria. Analysis of acute changes in venous hematocrit using a simple mathematical model. J Clin Invest 1990, 86:793-800

3. Hanson J, Lam SW, Mahanta KC, Pattnaik R, Alam S, Mohanty S, Hasan MU, Hossain A, Charunwatthana P, Chotivanich K, Maude RJ, Kingston H, Day NP, Mishra S, White NJ, Dondorp AM: Relative contributions of macrovascular and microvascular dysfunction to disease severity in falciparum malaria. $\mathrm{J}$ Infect Dis 2012, 206:571-579.

4. Hanson J, Lee SJ, Mohanty S, Faiz MA, Anstey NM, Charunwatthana P, Yunus EB, Mishra SK, Tjitra E, Price RN, Rahman R, Nosten F, Htut Y, Hoque G, Hong Chau TT, Hoan Phu N, Hien TT, White NJ, Day NP, Dondorp AM: A simple score to predict the outcome of severe malaria in adults. Clin Infect Dis 2010, 50:679-685.

5. Levy MM, Dellinger RP, Townsend SR, Linde-Zwirble WT, Marshall JC, Bion J, Schorr C, Artigas A, Ramsay G, Beale R, Parker MM, Gerlach H, Reinhart K, Silva E, Harvey M, Regan S, Angus DC, Surviving Sepsis Campaign: The Surviving Sepsis Campaign: results of an international guideline-based performance improvement program targeting severe sepsis. Crit Care Med 2010, 38:367-374.

6. Wills BA, Nguyen MD, Ha TL, Dong TH, Tran TN, Le TT, Tran VD, Nguyen TH, Nguyen VC, Stepniewska K, White NJ, Farrar JJ: Comparison of three fluid solutions for resuscitation in dengue shock syndrome. N Engl J Med 2005, 353:877-889.

7. Harris JB, LaRocque RC, Qadri F, Ryan ET, Calderwood SB: Cholera. Lancet 2012, 379:2466-2476.

8. Hanson J, Lee SJ, Mohanty S, Faiz MA, Anstey NM, Price RN, Charunwatthana P, Yunus EB, Mishra SK, Tjitra E, Rahman R, Nosten F, Htut Y, Maude RJ, Chau TT, Phu NH, Hien TT, White NJ, Day NP, Dondorp AM: Rapid clinical assessment to facilitate the triage of adults with falciparum malaria, a retrospective analysis. PLoS One 2014, 9:e87020.

9. White NJ, Turner GD, Day NP, Dondorp AM: Lethal malaria: Marchiafava and Bignami were right. J Infect Dis 2013, 208:192-198.

10. Davis TM, Suputtamongkol Y, Spencer JL, Ford S, Chienkul N, Schulenburg WE, White NJ: Measures of capillary permeability in acute falciparum malaria: relation to severity of infection and treatment. Clin Infect Dis 1992, 15:256-266.

11. Taylor WR, Hanson J, Turner GD, White NJ, Dondorp AM: Respiratory manifestations of malaria. Chest 2012, 142:492-505.

12. World Health Organization: Guidelines for the Treatment of Malaria. Geneva, Switzerland: World Health Organization; 2010.

13. Hall A: Dangers of high-dose quinine and overhydration in severe malaria. Lancet 1985, 1:1453-1454.

14. Warrell DA, White NJ, Looareesuwan S, Phillips RE, Warrell MJ, Bunnag D, Harinasuta KT: The treatment of severe falciparum malaria. Br Med J 1985, 291:1573-1574.

15. McGee S, Abernethy WB 3rd, Simel DL: The rational clinical examination. Is this patient hypovolemic? JAMA 1999, 281:1022-1029.

16. Saugel B, Ringmaier S, Holzapfel K, Schuster T, Phillip V, Schmid RM, Huber W: Physical examination, central venous pressure, and chest radiography for the prediction of transpulmonary thermodilution-derived hemodynamic parameters in critically ill patients: a prospective trial. J Crit Care 2011, 26:402-410.
17. Hanson J, Lam SW, Alam S, Pattnaik R, Mahanta KC, Uddin Hasan M, Mohanty S, Mishra S, Cohen S, Day N, White N, Dondorp A: The reliability of the physical examination to guide fluid therapy in adults with severe falciparum malaria: an observational study. Malar J 2013, 12:348.

18. Nguyen HP, Hanson J, Bethell D, Nguyen TH, Tran TH, Ly VC, Pham PL, Dinh XS, Dondorp A, White N, Tran TH, Day N: A retrospective analysis of the haemodynamic and metabolic effects of fluid resuscitation in Vietnamese adults with severe falciparum malaria. PLoS One 2011, 6:e25523.

19. Hanson J, Lam SW, Mohanty S, Alam S, Hasan MM, Lee SJ, Schultz MJ, Charunwatthana P, Cohen S, Kabir A, Mishra S, Day NP, White NJ, Dondorp AM: Central venous catheter use in severe malaria: time to reconsider the World Health Organization guidelines? Malar J 2011, 10:342.

20. Fein IA, Rackow EC, Shapiro L: Acute pulmonary edema in Plasmodium falciparum malaria. Am Rev Respir Dis 1978, 118:425-429.

21. Brooks MH, Kiel FW, Sheehy TW, Barry KG: Acute pulmonary edema in falciparum malaria - a clinicopathological correlation. N Engl J Med 1968, 279:732-737.

22. Aursudkij B, Wilairatana P, Vannaphan S, Walsh DS, Gordeux VR, Looareesuwan S: Pulmonary edema in cerebral malaria patients in Thailand. Southeast Asian J Trop Med Public Health 1998, 29:541-545.

23. World Health Organization: Management of Severe Malaria: A Practical Handbook. 3rd edition. Geneva, Switzerland: World Health Organization; 2012.

24. Marik PE, Cavallazzi R: Does the central venous pressure predict fluid responsiveness? An updated meta-analysis and a plea for some common sense. Crit Care Med 2013, 41:1774-1781.

25. Hanson JP, Lam SW, Mohanty S, Alam S, Pattnaik R, Mahanta KC, Hasan MU, Charunwatthana P, Mishra SK, Day NP, White NJ, Dondorp AM: Fluid resuscitation of adults with severe falciparum malaria: effects on acidbase status, renal function, and extravascular lung water. Crit Care Med 2013, 41:972-981.

26. Sitprija V, Indraprasit S, Pochanugool C, Benyajati C, Piyaratn P: Renal failure in malaria. Lancet 1967, 1:185-188.

27. Dondorp AM, Pongponratn E, White NJ: Reduced microcirculatory flow in severe falciparum malaria: pathophysiology and electron-microscopic pathology. Acta Trop 2004, 89:309-317.

28. Dondorp AM, Ince C, Charunwatthana P, Hanson J, van Kuijen A, Faiz MA Rahman MR, Hasan M, Bin Yunus E, Ghose A, Ruangveerayut R, Limmathurotsakul D, Mathura K, White NJ, Day NP: Direct in vivo assessment of microcirculatory dysfunction in severe falciparum malaria. J Infect Dis 2008, 197:79-84.

29. Maude RJ, Beare NA, Abu Sayeed A, Chang CC, Charunwatthana P, Faiz MA, Hossain A, Yunus EB, Hoque MG, Hasan MU, White NJ, Day NP, Dondorp AM: The spectrum of retinopathy in adults with Plasmodium falciparum malaria. Trans R Soc Trop Med Hyg 2009, 103:665-671.

30. Nguansangiam S, Day NP, Hien TT, Mai NT, Chaisri U, Riganti M, Dondorp AM, Lee SJ, Phu NH, Turner GD, White NJ, Ferguson DJ, Pongponratn E: A quantitative ultrastructural study of renal pathology in fatal Plasmodium falciparum malaria. Trop Med Int Health 2007, 12:1037-1050.

31. Ponsford MJ, Medana IM, Prapansilp P, Hien TT, Lee SJ, Dondorp AM, Esiri MM, Day NP, White NJ, Turner GD: Sequestration and microvascular congestion are associated with coma in human cerebral malaria. $J$ Infect Dis 2012, 205:663-671.

32. Trang $\Pi$, Phu NH, Vinh H, Hien TT, Cuong BM, Chau TT, Mai NT, Waller DJ, White NJ: Acute renal failure in patients with severe falciparum malaria. Clin Infect Dis 1992, 15:874-880.

33. Hanson J, Hasan MM, Royakkers AA, Alam S, Charunwatthana P, Maude RJ, Douthwaite ST, Yunus EB, Mantha ML, Schultz MJ, Faiz MA, White NJ, Day $N P$, Dondorp AM: Laboratory prediction of the requirement for renal replacement in acute falciparum malaria. Malar J 2011, 10:217.

34. Krishnan A, Karnad DR: Severe falciparum malaria: an important cause of multiple organ failure in Indian intensive care unit patients. Crit Care Med 2003, 31:2278-2284.

35. Hughes KR, Biagini GA, Craig AG: Continued cytoadherence of Plasmodium falciparum infected red blood cells after antimalarial treatment. Mol Biochem Parasitol 2010, 169:71-78.

36. Maude RJ, Barkhof F, Hassan MU, Ghose A, Hossain A, Abul Faiz M, Choudhury E, Rashid R, Abu Sayeed A, Charunwatthana P, Plewes K, Kingston H, Maude RR, Silamut K, Day NP, White NJ, Dondorp AM: Magnetic resonance imaging of the brain in adults with severe falciparum malaria. Malar J 2014, 13:177.

37. Yeo TW, Lampah DA, Gitawati R, Tjitra E, Kenangalem E, Piera K, Price RN, Duffull SB, Celermajer DS, Anstey NM: Angiopoietin-2 is associated with 
decreased endothelial nitric oxide and poor clinical outcome in severe falciparum malaria. Proc Natl Acad Sci U S A 2008, 105:17097-17102.

38. Weinbaum S, Tarbell JM, Damiano ER: The structure and function of the endothelial glycocalyx layer. Annu Rev Biomed Eng 2007, 9:121-167.

39. Marks ME, Armstrong M, Suvari MM, Batson S, Whitty JM, Chiodini PL, Bellinghan G, Doherty JF: Severe imported falciparum malaria among adults requiring intensive care: a retrospective study at the hospital for tropical diseases. London BMC Infect Dis 2013, 13:118.

40. Blumberg L, Lee RP, Lipman J, Beards S: Predictors of mortality in severe malaria: a two year experience in a non-endemic area. Anaesth Intensive Care 1996, 24:217-223

41. Phu NH, Hien TT, Mai NT, Chau TT, Chuong LV, Loc PP, Winearls C, Farrar J, White N, Day N: Hemofiltration and peritoneal dialysis in infectionassociated acute renal failure in Vietnam. N Engl J Med 2002, 347:895-902.

42. Wiedemann HP, Wheeler AP, Bernard GR, Thompson BT, Hayden D, de Boisblanc $B$, Connors AF Jr, Hite RD, Harabin AL: Comparison of two fluid-management strategies in acute lung injury. N Engl J Med 2006, 354:2564-2575.

43. Sahu S, Mohanty NK, Rath J, Patnaik SB: Spectrum of malaria complications in an intensive care unit. Singapore Med J 2010, 51:226-229.

44. Gachot B, Wolff M, Nissack G, Veber B, Vachon F: Acute lung injury complicating imported Plasmodium falciparum malaria. Chest 1995, 108:746-749.

45. Santos LC, Abreu CF, Xerinda SM, Tavares M, Lucas R, Sarmento AC: Severe imported malaria in an intensive care unit: a review of 59 cases. Malar $J$ 2012, 11:96.

46. Dondorp AM, Lee SJ, Faiz MA, Mishra S, Price R, Tjitra E, Than M, Htut Y, Mohanty S, Yunus EB, Rahman R, Nosten F, Anstey NM, Day NP, White NJ: The relationship between age and the manifestations of and mortality associated with severe malaria. Clin Infect Dis 2008, 47:151-157.

47. Planche $T$, Onanga M, Schwenk A, Dzeing A, Borrmann S, Faucher JF, Wright A, Bluck L, Ward L, Kombila M, Kremsner PG, Krishna S: Assessment of volume depletion in children with malaria. PLoS Med 2004, 1:e18.

48. Beare NA, Harding SP, Taylor TE, Lewallen S, Molyneux ME: Perfusion abnormalities in children with cerebral malaria and malarial retinopathy. $\mathrm{J}$ Infect Dis 2009, 199:263-271.

49. Conroy AL, Glover SJ, Hawkes M, Erdman LK, Seydel KB, Taylor TE, Molyneux $M E$, Kain KC: Angiopoietin-2 levels are associated with retinopathy and predict mortality in Malawian children with cerebral malaria: a retrospective case-control study. Crit Care Med 2012, 40:952-959.

50. White VA: Malaria in Malawi: inside a research autopsy study of pediatric cerebral malaria. Arch Pathol Lab Med 2011, 135:220-226.

51. Maitland K, Kiguli S, Opoka RO, Engoru C, Olupot-Olupot P, Akech SO, Nyeko R, Mtove G, Reyburn H, Lang T, Brent B, Evans JA, Tibenderana JK, Crawley J, Russell EC, Levin M, Babiker AG, Gibb DM, FEAST Trial Group: Mortality after fluid bolus in African children with severe infection. N Engl J Med 2011, 364:2483-2495.

52. Maitland K, George EC, Evans JA, Kiguli S, Olupot-Olupot P, Akech SO, Opoka $\mathrm{RO}$, Engoru C, Nyeko R, Mtove G, Reyburn H, Brent B, Nteziyaremye J, Mpoya A, Prevatt N, Dambisya CM, Semakula D, Ddungu A, Okuuny V, Wokulira R, Timbwa M, Otii B, Levin M, Crawley J, Babiker AG, Gibb DM, FEAST trial group: Exploring mechanisms of excess mortality with early fluid resuscitation: insights from the FEAST trial. BMC Med 2013, 11:68.

53. Boyd JH, Forbes J, Nakada TA, Walley KR, Russell JA: Fluid resuscitation in septic shock: a positive fluid balance and elevated central venous pressure are associated with increased mortality. Crit Care Med 2011, 39:259-265.

54. Vincent JL, Sakr Y, Sprung CL, Ranieri VM, Reinhart K, Gerlach H, Moreno R, Carlet J, Le Gall JR, Payen D: Sepsis in European intensive care units: results of the SOAP study. Crit Care Med 2006, 34:344-353.

55. Uchino S, Bellomo R, Morimatsu H, Sugihara M, French C, Stephens D, Wendon J, Honore P, Mulder J, Turner A: Pulmonary artery catheter versus pulse contour analysis: a prospective epidemiological study. Crit Care 2006, 10:R174.

56. RENAL Replacement Therapy Study Investigators, Bellomo R, Cass A, Cole L, Finfer S, Gallagher M, Lee J, Lo S, McArthur C, McGuiness S, Norton R, Myburgh J, Scheinkestel C, Su S: An observational study fluid balance and patient outcomes in the Randomized Evaluation of Normal vs. Augmented Level of Replacement Therapy trial. Crit Care Med 2012, 40:1753-1760.

57. Wang $\mathrm{CH}$, Hsieh WH, Chou HC, Huang YS, Shen JH, Yeo YH, Chang HE, Chen SC, Lee CC: Liberal versus restricted fluid resuscitation strategies in trauma patients: a systematic review and meta-analysis of randomized controlled trials and observational studies. Crit Care Med 2014, 42:954-961.
58. Lobo DN, Stanga Z, Aloysius MM, Wicks C, Nunes QM, Ingram KL, Risch L, Allison SP: Effect of volume loading with 1 liter intravenous infusions of $0.9 \%$ saline, $4 \%$ succinylated gelatine (Gelofusine) and $6 \%$ hydroxyethyl starch (Voluven) on blood volume and endocrine responses: a randomized, three-way crossover study in healthy volunteers. Crit Care Med 2010, 38:464-470.

59. Jacob M, Chappell D, Hofmann-Kiefer K, Helfen T, Schuelke A, Jacob B, Burges A, Conzen P, Rehm M: The intravascular volume effect of Ringer's lactate is below 20\%: a prospective study in humans. Crit Care 2012, 16:R86.

60. Cordemans C, De Laet I, Van Regenmortel N, Schoonheydt K, Dits H, Huber W, Malbrain ML: Fluid management in critically ill patients: the role of extravascular lung water, abdominal hypertension, capillary leak, and fluid balance. Ann Intensive Care 2012, 2:S1.

61. Butcher BW, Liu KD: Fluid overload in AKI: epiphenomenon or putative effect on mortality? Curr Opin Crit Care 2012, 18:593-598.

62. Durairaj L, Schmidt GA: Fluid therapy in resuscitated sepsis: less is more. Chest 2008, 133:252-263.

63. Hilton AK, Bellomo R: A critique of fluid bolus resuscitation in severe sepsis. Crit Care 2012, 16:302

64. Dellinger RP, Levy MM, Rhodes A, Annane D, Gerlach H, Opal SM, Sevransky JE, Sprung CL, Douglas IS, Jaeschke R, Osborn TM, Nunnally ME, Townsend SR, Reinhart K, Kleinpell RM, Angus DC, Deutschman CS, Machado FR, Rubenfeld GD, Webb SA, Beale RJ, Vincent JL, Moreno R, Surviving Sepsis Campaign Guidelines Committee including the Pediatric Subgroup: Surviving Sepsis Campaign: international guidelines for management of Severe Sepsis and Septic Shock: 2012. Crit Care Med 2013, 41:580-637.

65. Castellanos-Ortega A, Suberviola B, Garcia-Astudillo LA, Holanda MS, Ortiz F, Llorca J, Delgado-Rodriguez M: Impact of the Surviving Sepsis Campaign protocols on hospital length of stay and mortality in septic shock patients: results of a three-year follow-up quasi-experimental study. Crit Care Med 2010, 38:1036-1043.

66. Machado FR, Freitas FG: Controversies of surviving sepsis campaign bundles: should we use them? Shock 2008, 30:34-40.

67. Ferrer R, Artigas A, Suarez D, Palencia E, Levy MM, Arenzana A, Perez XL, Sirvent JM: Effectiveness of treatments for severe sepsis: a prospective, multicenter, observational study. Am J Respir Crit Care Med 2009, 180:861-866.

68. Hayes MA, Timmins AC, Yau EH, Palazzo M, Hinds CJ, Watson D: Elevation of systemic oxygen delivery in the treatment of critically ill patients. N Engl J Med 1994, 330:1717-1722.

69. Yunos NM, Kim IB, Bellomo R, Bailey M, Ho L, Story D, Gutteridge GA, Hart GK: The biochemical effects of restricting chloride-rich fluids in intensive care. Crit Care Med 2011, 39:2419-2424.

70. Raghunathan K, Shaw A, Nathanson B, Sturmer T, Brookhart A, Stefan MS, Setoguchi S, Beadles C, Lindenauer PK: Association between the choice of IV crystalloid and in-hospital mortality among critically ill adults with sepsis. Crit Care Med 2014, 42:1585-1591.

71. Perel P, Roberts I, Ker K: Colloids versus crystalloids for fluid resuscitation in critically ill patients. Cochrane Database Syst Rev 2013, 2:CD000567.

72. Finfer S, Bellomo R, Boyce N, French J, Myburgh J, Norton R: A comparison of albumin and saline for fluid resuscitation in the intensive care unit. N Engl J Med 2004, 350:2247-2256.

73. Anstey NM, Douglas NM, Poespoprodjo JR, Price RN: Plasmodium vivax: clinical spectrum, risk factors and pathogenesis. Adv Parasitol 2012, 80:151-201

74. Singh B, Daneshvar C: Human infections and detection of Plasmodium knowlesi. Clin Microbiol Rev 2013, 26:165-184.

\section{doi:10.1186/s13054-014-0642-6}

Cite this article as: Hanson et al:: The fluid management of adults with severe malaria. Critical Care 2014 18:642. 